\title{
Transcriptomic Nnalysis Reveals the Mechanism of Host Growth Promotion by Endophytic Fungus of Rumex Gmelinii Turcz.
}

\section{Ding Changhong (D 598808726@qq.com )}

Heilongjiang University of Chinese Medicine https://orcid.org/0000-0002-1502-9434

\section{Shouyu Wang}

Heilongjiang University of Chinese Medicine

Jiabin Li

Heilongjiang University of Chinese Medicine

Zhenyue Wang

Heilongjiang University of Chinese Medicine

\section{Research Article}

Keywords: Rumex gmelinii Turcz. (RGT), endophytic fungus, growth promoting, transcriptome, mechanism

Posted Date: March 18th, 2021

DOl: https://doi.org/10.21203/rs.3.rs-335595/v1

License: (9) (1) This work is licensed under a Creative Commons Attribution 4.0 International License. Read Full License 


\section{Transcriptomic analysis reveals the mechanism of host growth promotion by endophytic \\ 2 fungus of Rumex gmelinii Turcz.}

3 Changhong Ding*, Shouyu Wang, Jiabin Li and Zhenyue Wang

4 College of pharmacy, Heilongjiang University of Traditional Chinese Medicine, Harbin, China

5 * Correspondence:

6 Changhong Ding, E-mail: 598808726@qq.com, Tel:13895755206

7 Abstract-Rumex gmelinii Turcz. (RGT) is a medicinal plant of Rumex in Polygonaceae. Our research group isolated an 8 endophytic fungus plectosaphaerella cucumerina (Strain J-G) from RGT, which could promote the growth of the host

9 significantly when was co-cultured with the host. In this study, we mainly used transcriptomic analysis to explore the

10 molecular mechanism of the growth promoting effect. It was found that during the process of co-culture with Strain J-G,

11 metabolism of amino acids, the synthesis and metabolism of carbohydrates in RGT tissue culture seedlings were all

12 promoted, which provided sufficient material and energy basis for the growth of plants. In addition, response to hormones

13 such as auxin and cytokinin in RGT tissue culture seedlings was improved significantly, which promoted the growth and

14 development of plants. The repairing ability of DNA in RGT tissue culture seedlings was also enhanced to provide a good

15 guarantee for the growth of plants. Meanwhile, defense system of RGT tissue culture seedlings was also mobilized by the

16 existence of Strain J-G, therefore more secondary metabolites and stress resistant substances were produced to ensure the

17 normal growth and metabolism of plants.

18 Keywords: Rumex gmelinii Turcz. (RGT); endophytic fungus; growth promoting; transcriptome; mechanism

19 Declarations

20 Funding

21 We are grateful to National key R \& D plan in the 13th five year plan (2016yfc50500300), Natural Science Foundation 22 of Heilongjiang Province (C2016053, LH2020H093), Scientific research project of traditional Chinese medicine in

23 Heilongjiang Province (general survey of traditional Chinese medicine resources 2018hljzyzypc-21), Project of "Support 
24 plan for young backbone teachers" of Heilongjiang University of traditional Chinese medicine (15041190011) for their

25 financial support.

\section{Conflicts of interest/Competing interests}

27 The authors declare no conflicts of interest.

28 Availability of data and material

29 The transcriptome data after filtering were submitted to SRA (SRR11308217)

30 Code availability

$31 \quad$ Not applicable

\section{Authors' contributions}

$33 \mathrm{CD}$ and $\mathrm{ZW}$ designed this research. KL, JL did a study on the growth promoting effect of endophyticfungus, CD, JL and

34 WS performed the related experimental research and analysis of transcriptome. CD and WS drafted the manuscript. All

35 authors re

36 Ethics approval

$37 \quad$ Not applicable

\section{Consent to participate}

39 Not applicable

40 Consent for publication

41 Not applicable ad and approved the final manuscript. 
43 Abstract-Rumex gmelinii Turcz. (RGT) is a medicinal plant of Rumex in Polygonaceae. Our research group isolated an

44 endophytic fungus plectosaphaerella cucumerina (Strain J-G) from RGT, which could promote the growth of the host

45 significantly when was co-cultured with the host. In this study, we mainly used transcriptomic analysis to explore the

46 molecular mechanism of the growth promoting effect. It was found that during the process of co-culture with Strain J-G,

47 metabolism of amino acids, the synthesis and metabolism of carbohydrates in RGT tissue culture seedlings were all

48 promoted, which provided sufficient material and energy basis for the growth of plants. In addition, response to hormones

49 such as auxin and cytokinin in RGT tissue culture seedlings was improved significantly, which promoted the growth and

50 development of plants. The repairing ability of DNA in RGT tissue culture seedlings was also enhanced to provide a good

51 guarantee for the growth of plants. Meanwhile, defense system of RGT tissue culture seedlings was also mobilized by the

52 existence of Strain J-G, therefore more secondary metabolites and stress resistant substances were produced to ensure the

53 normal growth and metabolism of plants.

\section{Introduction}

Rumex gmelinii Turcz. (RGT) is a medicinal plant of Rumex in Polygonaceae, which is distributed in Northeast and North of China. The root of RGT is used as medicine (Zhang GQ et al. 2008) which is cold-natured, bitter in taste, non-toxic, and beneficial to lung and heart. It can be used for the treatment of constipation, carbuncle, swelling, scabies and other diseases. It mainly contains resveratrol, polydatin, musizin, chrysophanol, emodin, physcion and other components (Wang ZY et al. 2009; Wang ZY et al. 2005).

Endophytic fungi widely exist in various tissues and organs of plants, such as roots, stems, leaves, and flowers, and can be separated from sterilized tissues or organs of plants (Guo SX 2008; Katoch M and Pull S 2017). Some endophytic fungi can promote plant growth (Jia M et al. 2016), enhance the ability of plants to resist adversity (Waqas et al. 2012) and increase the accumulation of effective components in plants (Xing XK 2018). In recent years, more and more attention has been paid to the role of endophytic fungi in promoting the growth of host. Some endophytic fungi that can promote the growth of the host have been screened from various medicinal plants, such as Rehmannia glutinosa (Chen BB et al. 2011), Salvia Miltiorrhiza (Zhou LS et al. 2018), Anoectochilus roxburghii (Zhou K et al. 2018), Artemisia аппиа (Wu XL et al. 2018) Santalum album 13 J et al. 2018). 
70 hormones of growth promoting, or promote the synthesis of certain plant hormones, it may also be associated with

71 various metabolisms. It is found that some endophytic fungi can produce plant hormones such as indoleacetic acid (IAA)

72 and gibberellin (GAs), which can promote the growth of plants 14 LS et al. 2019). There are also some endophytic fungi

73 have the abilities to fix nitrogen, dissolve phosphorus and dissolve potassium, which can increase the absorption of

74 inorganic elements such as nitrogen, phosphorus and potassium, so as to promote the growth of plants (Yuan M et al.

75 2016). Although many endophytic fungi that can promote the growth of plants have been found, there are few studies on

76 the mechanism of growth-promoting, which usually focuse on hormone 14 LS et al. 2019), enzyme activity (Prisana

77 Wonglom et al. 2020), and signal transduction (Sun X et al. 2020). But the organism is a whole, every biological

78 phenomenon may be associated with a variety of physiological processes, and is the result of a variety of reactions.

79 Therefore, we intended to use the method of omics to comprehensively study the growth-promoting mechanism of RGT

80 by Strain J-G.

81 The transcriptome is the sum of the transcriptional products of all genes in a particular organism in a certain state (Wang

82 XL et al. 2015; Zhag SB et al. 2014), which is the link between the genome and the proteome. The transcriptome focuses

83 on the expression of functional genes that can describe the molecular mechanism in biological processes. Now

84 transcriptome analysis has become a more mature and popular technology in the field of Biology. Through transcriptome

85 analysis, not only the high-throughput information of gene expression at RNA level can be obtained, but also the internal

86 relationship between gene expression and life phenomena can be revealed, so as to characterize the physiological activity

87 of life and determine its metabolic characteristics. Many researches have shown that transcriptome analysis is highly

88 feasible in studying the interaction mechanism between plants and fungi (Liu KH et al. 2017; Lamdan NL et al.2015).

89 The objective of this study was to explain the molecular mechanism of host growth promotion by Strain J-G of RGT

90 based on transcriptome analysis. In order to provide basis for the application of endophytic fungi.

\section{Materials and Methods}

\section{Isolation and Identification of Endophytic Fungus Strain J-G}

93 Strain J-G is an endophytic fungus isolated from RGT. The genomic DNA of Strain J-G was extracted and amplified the

94 ITS I sequence by PCR. Then the sequencing result was entered into GenBank for comparison. After that sequences with 
high homology to ITS I of Strain J-G were selected, downloaded, and input into the software MEGA5 to test. The method

96 of neighbor joining was used to establish phylogenetic tree.

\section{Study on the Growth-promoting Effect of Strain J-G}

RGT tissue culture seedlings with the same growth state were selected and implanted into MS solid medium, one seedling

100 per medium. These seedlings were placed in a light incubator, temperature (day / night) $25^{\circ} \mathrm{C} / 18^{\circ} \mathrm{C}$, photoperiod $14 / 10$

$101 \mathrm{~h}$, light intensity $3000 \mathrm{~lx}$, cultured for $5 \mathrm{~d}$. The Strain J-G was inoculated on the medium $2 \mathrm{~cm}$ away from the RGT tissue

102 culture seedling with an inoculating needle. Then these seedlings were placed in a light incubator, emperature (day /

103 night) $25^{\circ} \mathrm{C} / 18^{\circ} \mathrm{C}$, photoperiod $14 / 10 \mathrm{~h}$, light intensity $3000 \mathrm{~lx}$, co-cultured for $25 \mathrm{~d}$, six repetitions were set under the

104 same conditions. The other treatment conditions of the control group were the same except no inoculation of Strain J-G,

105 six repetitions were set under the same conditions. Three replicates of co-culture group and control group were used in

106 the study of physiological indicators, and the other three replicates were used in the analysis of transcriptome.

RNA Extraction

109 Total RNA of both co-culture group and the control group was extracted by Total RNA Extractor (Shanghai Shengong).

110 Integrity of RNA samples was detected by $1 \%$ agarose electrophoresis, and the purity of samples was detected by Keao

111 k5500 spectro-photometer. The concentration of RNA samples was detected by Agilent 2100 RNA Nano 6000 Assay Kit

112 (Agilent Technologies, CA, USA).

\section{Library Construction and Sequencing}

114 After the total RNA samples were detected qualified, the mRNAs were enriched by magnetic beads with Oligo (dT), and

115 fragment buffer was added to the obtained mRNAs to make the fragments into short fragments. The fragmented mRNAs

116 were used as templates to synthesize the first strands of cDNA with six base random primers. Then buffers, dNTPs,

117 RNaseH, and DNA Polymerase I were added to synthesize the second strand of cDNA continually. The obtained cDNAs

118 were purified by QIAQuickPCR kit and were eluted with EB buffer. After that, the double stranded cDNAs were treated

119 with terminal repair, added base A and sequencing connector. Finally, the target size fragments were recovered by 
120 agarose gel electrophoresis and were amplified by PCR to complete the entire library preparation. The constructed library

121 was sequenced using the Illumina platform, and the sequencing strategy was PE150.

122

\section{The Quality Control of the Data}

124 Raw data were processed with Perl scripts to ensure the quality of data used in further-analysis. The adopted filtering 125 criteria were as follows: 1) Removed the adaptor-polluted reads (Reads containing more than 5 adapter-polluted bases

126 were regarded as adaptor-polluted reads and would be filtered out); 2) Removed the low-quality reads (Reads with the

127 number of low quality bases $(\mathrm{Q} \leq 19)$ accounting for more than $15 \%$ of total bases were regarded as low-quality reads); 3$)$

128 Removed reads with number of $\mathrm{N}$ bases accounting for more than $5 \%$; As for paired-end sequencing data, both reads

129 would be filtered out if any read of the paired-end reads were adaptor-polluted.

130 The obtained clean data after filtering would be carried out on statistics analyses on its quality, data quantity and quality,

131 including Q30.

132

\section{Assembly, Coding Regions Prediction and annotation}

134 The software Trinity was used for assembly. TransDecoder was used to identify the open reading frame (ORF) of the 135 assembled transcripts. Trinotate was used to annotate the predicted ORF and transcripts.

138 Reads Count for each gene in each sample was counted by HTSeq v0.6.0, and RPKM (Reads Per Kilobase Millon

139 Mapped Reads) was then calculated to estimate the expression level of genes in each sample.The formula is shown as

$$
\mathrm{RPKM}=\frac{10^{6} * R}{N L / 10^{3}}
$$


$140 \mathrm{R}$ is the number of reads in a certain sample that is assigned to a certain gene, $\mathrm{N}$ is the total number of mapped reads in

141 the certain sample and L is the length of the certain. RPKM can eliminate the effect of sequencing depth and gene length

142 on gene expression levels.

\section{Analysis of Gene Different Expression}

144 DESeq2v1.4.5was used for differential gene expression analysis between two samples with biological replicates using a

145 model based on the negative binomial distribution. The P-value were assigned to each gene and adjusted by the

146 Benjamini and Hochberg approach for controlling the false discovery rate. Genes with $\mathrm{q} \leq 0.05$ and $\mid \log 2$ ratio $\mid \geq 1$ were

147 identified as differentially expressed genes (DEGs). Then heat maps were made based on the expression of samples.

\section{GO Analysis}

150 The GO (Gene Ontology, http://geneontology.org/) enrichment of DEGs was implemented by the hypergeometric test, in 151 which p-value was calculated and adjusted as q-value, and data backgrounds genes in the whole genome. GO terms with $152 \mathrm{q}<0.05$ were considered to be significantly enriched.

\section{KEGG Analysis}

155 The KEGG (Kyoto Encyclopedia of Genes and Genomes, http://www.kegg.jp/) enrichment of DEGs was implemented by 156 the hypergeometric test, in which p-value was adjusted by multiple comparisons as q-value. KEGG terms with q<0.05 157 were considered to be significantly enriched.

\section{Verification by Real-time PCR}

160 Real time PCR was used to detect the expression level of six genes in energy metabolism and plant hormone signal 161 transduction pathway of co-cultured RGT tissue culture seedlings. GAPDH was taken as internal reference gene. The 
162 gene expressions of Phenylalanine aminolyase (PAL), Cinnamoyl coenzyme A reductase (CCR), $\beta$ - fructofuranosidase

163 (INV), Starch synthetase (GlgA), Auxin response protein IAA(IAA) and Cytokinin receptor (CYT) were detected.

164 Bio-Rad iQ-5 Fluorescence Quantitative Analyzer provided CT values of target genes and internal reference gene after

165 amplifications were completed. Gene expressions were calculated by $2^{-\Delta \Delta \mathrm{CT}} . \triangle \triangle \mathrm{CT}=(\mathrm{CT}$ Objective $-\mathrm{CT}$

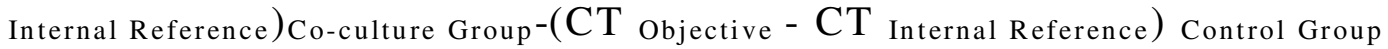

\section{Results}

169 The blast comparison of ITS I sequence showed that the Strain J-G was 100\% similar to plectosaphaerella cucumerina.

170 The sequence obtained has been submitted to GenBank, No. mt068424. In the NJ tree (Fig. 1-A), Strain J-G was in the

171 same branch with Plectosphaerella cucumerina (EU030361.1). Therefore, Strain J-G was identified as Plectosphaerella

172 cucumerina. The colony of its Strain was white with regular edges and dense mycelia (Fig. 1-B). Strain J-G was deposited

173 in the Traditional Chinese Medicine Resources Laboratory of Heilongjiang University of Traditional Chinese Medicine.

174 Compared with the control group, the fresh weight of the roots of co-cultured RGT tissue culture seedlings increased by

$175176 \%$ (Fig. 2-A), and the dry weight of roots increased by $161 \%$ (Fig. 2-B). These two differences were significant. Both

176 the fresh weight and dry weight of the above-ground parts of co-cultured group were significantly higher than that of the

177 control group (Fig. 2-C, D). Thus, it could be seen that the growth promoting effect of Strain J-G on host was

178 comprehensive and significant.

\section{RNA Extraction and Detection}

180 The results of RNA extraction and detection were shown in the Table 1. The Detection from all aspects showed that the

181 quality of total RNA of both the co-cultured group (G1a, G1b, G1c) and the control group (C1a, C1b, C1c) was qualified,

182 and downstream experiments could be carried out. 
186 The transcriptome data after filtering were submitted to SRA (SRR11308217), the test results of it were shown in Fig.3.

187 The total numbers of filtered high-quality sequences of the three replicates (G1a, G1b, G1c) in the co-cultured group were $18863,700,940,63,696,030$, and 63,412,070. The proportions of the filtered high-quality sequences to the original ones were $18995.71 \%, 95.03 \%$ and $94.82 \%$, which indicated that the sequencing qualities were acceptable. The total numbers of filtered 190 high-quality sequences of the three replicates $(\mathrm{C} 1 \mathrm{a}, \mathrm{C} 1 \mathrm{~b}, \mathrm{C} 1 \mathrm{c})$ in the control group were $61,116,748,56,930,540$, and $19158,908,308$. The proportions of the filtered high-quality sequences to the original ones were $97.45 \%, 97.25 \%$, and $19297.82 \%$, which indicated that the sequencing qualities were acceptable.

\section{The Basic Situation of Gene Different Expression}

194 According to the expression analysis, there were a total of 34,553 significantly different expressed unigenes between co195 cultured group and the control, of which 25,756 were up-regulated and 8,797 were down-regulated.

196 According to the comparison between co-cultured group and the control, the scatter diagrams of log2foldchange of 197 multiples of gene expression differences were obtained (Fig. 3). In Fig. 3, the yellow dots represented genes that were 198 significantly up-regulated and the blue dots represented the genes that were significantly down-regulated, while the gray 199 dots represented the other genes that were not significant differentially expressed. It was showed that the up-regulated 200 genes had more significant expression differences.

\section{The Results of Go Analysis}

202

The bubble diagram of the ten GO items with the highest significance of unigenes enrichment in Biological Process (BP)

203 were shown in Fig. 4. The larger the bubble was, the higher the Rich_Ratio was, the redder the color was, the higher

204 degree of enrichment was. It could be seen from Fig. 4 that the unigenes in the ten items, such as metabolic process,

205 heterocycle biosynthetic process and organic cyclic compound biosynthetic process were more annotated, among which

206 the most annotated and enriched item was the metabolic process. 
211 The bubble diagram of the ten GO items with the highest significance of unigenes enrichment in Molecular Function(MF)

212 were shown in Fig.4. It showed that the unigenes in the ten items, such as catalytic activity, transition metal ion binding

213 and DNA binding were more annotated, among which the most annotated and enriched item was the catalytic

214 activity.The statistics of annotation results of different expressed unigenes in secondary Go items were shown in Fig.5.

215 The horizontal ordinate was the secondary Go items with different expressed unigenes annotation. The left ordinate

216 indicated the proportion of up-regulated different expressed unigenes /down-regulated different expressed unigenes. The

217 right ordinate indicated the quantitis of up-regulated different expressed unigenes /down-regulated different expressed

218 unigenes, among which there were significant differences in gene expression of cellular component, biological process,

219 and molecular function. In terms of the distribution, the different expressed unigenes in cellular component and biological

220 process were more obvious.

\section{The Results of KEGG Analysis}

222 All the samples enriched KO were combined and the distribution diagram was made according to the enrichment

223 significance q value of the sample in the KO (Fig.6). It was shown that pathways of Phenylpropanoid biosynthesis,

224 Cyanoamino acid metabolism, Tyrosine metabolism, Starch and sucrose metabolism, Phenylalanine metabolism, Steroid

225 biosynthesis, Base excision repair, Pentose and glucuronate interconversions, Plant hormone signal transduction,

226 Biosynthesis of unsaturated fatty acids, alpha-Linolenic acid Glycine, serine and threonine metabolism, Isoquinoline

227 alkaloid biosynthesis were significantly enriched.

\section{Gene Expression differences of co-cultured RGT tissue culture seedlings}

229 By comparing the differentially expressed unigenes between the control group and the co-cultured group, it was found

230 that there were significant differences in gene expression in many pathways, such as Phenylalanine biosynthesis pathway,

231 Phenylalanine metabolism, Starch and sucrose metabolism, Plant hormone signal transduction and so on.

232 In the pathway of Phenylpropanol biosynthesis (Table 2), unigenes homologous to genes of phenylalanine ammonia lyase 233 (PAL) were up-regulated, while unigenes homologous to cinnamoyl-CoA reductase (CCR) and shikimic acid o-

234 hydroxycinnamoyl transferase [EC:2.3.1.133] were significantly down-regulated. Under these circumstances the

235 formation of resveratrol and polydatin could be promoted through the enzymatic reaction. 
In Cyanamide acid metabolism pathway (Table 2), unigenes homologous to genes of Formamidase [EC: 3.5.1.49] were

237 up-regulated, which promoted $\mathrm{NH}_{3}$ synthesis and nitrogen metabolism. Unigenes homologous to glycine methyl

238 transferase (GlyA) were up-regulated, which promoted the metabolism and transformation of glycine, serine, threonine

239 and cysteine.

240 In the Tyrosine pathway (Table 2), it was observed that unigenes homologous to genes of tyrosine aminotransferase [EC:

241 2.6.1.5], aromatic amino acid aminotransferase I [EC: 2.6.1.57], phosphohistidine aminotransferase (HisC) and aspartate

242 aminotransferase[EC:2.6.1.1] were up-regulated. The mutual transformation of 4-hydroxy-phenylpyruvate with tyrosine

243 could be promoted by these enzymes. Unigenes homologous to genes of 4-hydroxyphenylpyruvate dioxygenase (HPD),

244 maleylacetate isomerase (MaiA), fumarylacetoacetase [EC:3.7.1.2] and other enzymes were up-regulated, which could

245 catalyze the synthesis of acetoacetate and fumarate, and eventually fumarate entered the citric acid cycle to promote the

246 material metabolism and energy formation. Meanwhile, unigenes homologous to genes of 4- hydroxy-2 - oxyheptanediate

247 aldehydase (Hpal) and succinate semialdehyde dehydrogenase/glutarate semialdehyde dehydrogenase (GabD) were up-

248 regulated, which could catalyze the conversion of 2, 4-dihydroxyhept-2-enedioate to succinate, then succinate entered the

249 citric acid cycle to enhance the material metabolism and energy formation. In addition, unigenes homologous to genes of

250 monoamine oxidase, alcohol dehydrogenase and aldehyde dehydrogenase (NAD $(\mathrm{P})+$ ) [EC: 1.2.1.5] were up-regulated,

251 which could promote the metabolism and conversion of amino acids, in order to provide more materials for the growth of

252 RGT tissue culture seedlings.

253 In Glycine, serine and threonine Metabolism, 78 unigenes homologous to genes of Amino acid invertases were up-

254 regulated, which enhanced the metabolism and conversion of amino acids.

255 In Starch and sucrose metabolism (Table 2), unigenes homologous to genes of $\beta$-fructofuranosidase (INV) were up-

256 regulated, which could promote the formation of 6-phosphate-glucose. Unigenes homologous to genes of $\alpha$-glucosidase

257 [EC: 3.2.1.20] were up-regulated, which could produce more fructose and glucose. Unigenes homologous to genes of

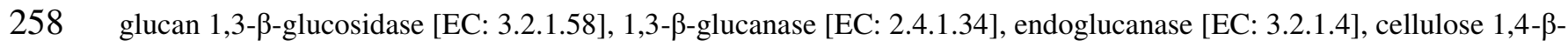

259 fibreglucosidase [EC: 3.2.1.91], $\alpha$ - trehalase [EC: 3.2.1.28] were up-regulated, which could catalyze the conversion of

260 glucoside, cellulose, and trehalose to glucose. Therefore, substrates of respiration increased for energy provision of RGT

261 tissue culture seedlings. Meanwhile, unigenes homologous to genes of starch synthetase (GlgA), 1,4- $\alpha$-glucan branching

262 enzyme [EC: 2.4.1.18] were up-regulated, which could catalyze the synthesis of starch. Therefore, it could be seen that 
the co-culture of the Strain J-G and RGT tissue culture seedlings not only promoted the formation of glucose, but also

264 enhanced the accumulation of starch.

265 In the Pentose and glucuronide interconversion pathway (Table 2), unigenes homologous to genes of galacturonidase

266 [EC:3.2.1.67] were up-regulated, which could catalyze diaminogalactose to form galactose, and galactose could

267 participate in various metabolisms. Unigenes homologous to genes of L-threonine-3-deoxyhexanoic acid aldolase

268 (GAAC) were up-regulated, which was beneficial for galactose to enter into the glycerol metabolism pathway and

269 provide more energy for the growth of RGT tissue culture seedlings. Unigenes homologous to genes of alcohol

270 dehydrogenase (NADP+) (AKR1A1) were up-regulated, which could catalyze gulonic acid to form more D-Glucuronate.

271 Meanwhile, unigenes homologous to genes of UTP-glucose-1-phosphouridinyltransferase (UGP2) and UDP-glucose-6-

272 dehydrogenase (UGDH) were up-regulated, which could catalyze the production of glycolysis-- fructose phosphate to

273 form more UDP-D-Glucuronate. And unigenes homologous to genes of UDP glycopyrophosphorylase (USP),

274 glucuronosyl transferase (UGT), $\beta$-glucuronidase [EC: 3.2.1.31] were also up-regulated, which could promote the

275 formation of glucoronate. As a result, a larger amount of glucoronate was produced to provide more materials for

276 synthesis of aminosaccharide and ribose.

277 In the Steroid biosynthetic pathway (Table 2), unigenes homologous to genes of farnesyl diphosphate farnesyl transferase

278 (FDFT1) were down-regulated. It could be inferred that biosynthesis of steroid would be inhibited to some extent.

279 In Basal resection and repair processes, 38 unigenes homologous to genes of most enzymes used in eukaryotic basal

280 resection and repair were significantly up-regulated, only 13 unigenes homologous to genes of DNA-3-methyladenine

281 glycosylase (MPG) and poly (ADP ribose) polymerase (PARP) were down-regulated. It could be inferred that the repair

282 function of DNA was improved.

283 In the Plant hormone signal transduction pathway (Table 2), unigenes homologous to genes of auxin influx carrier

284 (AUX1 LAX family), auxin-responsive protein IAA (IAA), auxin response factor (k4486), auxin responsive GH3 gene

285 family(GH3) and SAUR family protein (SAUR) were up-regulated, while unigenes homologous to genes of transport

286 inhibitor responder 1 (TIR1) were down-regulated, which promoted the response of cells to growth-promoting hormones,

287 so as to accelerate the growth of RGT tissue culture seedlings. Unigenes homologous to genes of arabidopsis histidine

288 kinase 2/3/4 (cytokinin receptor) (AHK2_3), histidine-containing phosphotransfer peotein (AHP), two-component

289 response regulator ARR-B family (ARR-B) and two-component response regulator ARR-A family were up-regulated, 
which could enhance the response of RGT tissue culture seedlings to cytokinin, thereby cell division of seedlings was

291 promoted. Unigenes homologous to genes of ethylene-insensitive protein 2 (EIN2), ethylene-insensitive protein 2 (EBF1

292 2), ethylene-responsive transcription factor 1 (ERF1) were down-regulated, which could delay plant senescence.

293 Unigenes homologous to genes of BAK1, BRI1, BSK, TCH4, and CYCD3 that played an important role in the response

294 of brassinosteroids were up-regulated, which could promote cell growth and cell division of RGT tissue culture seedlings.

295 Unigenes homologous to genes of jasmonic acid-amino synthetase (JAR1) were up-regulated, which could promote

296 synthesis of jasmonic acid. Unigenes homologous to genes of coronatine-insensitive protein 1 (COI-1), jasmonate ZIM

297 domain-containing protein (JAZ) and transcription factor MYC2 (MYC2) were up-regulated. Because jasmonic acid can

298 induce the expression of resistance genes, these differential expression of genes might be related to the infection of Strain

299 J-G. Meanwhile, unigenes homologous to genes of regulatory protein NPR1 (NPR1) and the transcription factor TGA

300 which were also related to the improvement of plant disease resistance were up-regulated, it could be related to the

301 infection of endophytic fungus and the resistance of the host.

302 In the Biosynthesis of unsaturated fatty acids, 26 unigenes were up-regulated and 13 unigenes were down-regulated,

303 among which unigenes homologous to genes of acyl-CoA thioesterase 7[EC:3.1.2.2] and acyl-CoA thioesterase II (TesB)

304 were up-regulated. These enzymes could catalyze the synthesis of $\alpha$-linolenic acid, hexadecanoic acid, stearic acid and

305 oleic acid, which played an important role in the resistance of plants.

Verification of the expression of Key Genes in co-cultured RGT tissue culture seedlings

307 In order to verify the results of transcriptome analysis and further explore the effect of co-culture on the growth process

308 and secondary metabolites of RGT tissue culture seedlings, six genes of key enzymes, such as genes of phenylalanine

309 ammonia lyase (PAL), cinnamoyl COA reductase (CCR), $\beta$-fructofuranosidase (INV), starch synthase (GlgA), auxin

310 response protein IAA ( IAA), cytokinin receptor (CYT) of RGT tissue culture seedlings were selected for quantitatively

311 analysis of expression by real-time PCR.

312 As can be seen from the results (Fig. 7), genes of PAL, INV, GlgA, IAA, CYT were significantly up-regulated in co-

313 cultured group and gene of CCR was significantly down-regulated compared with the control group. The results of these

314 gene expression tests were consistent with those of the transcriptome analysis.

316 Discussion 
317 PAL is an important regulatory enzyme in secondary metabolism, whose activity is controlled by many internal and

318 external factors. The infection of viruses, bacteria and fungi can increase the expression of PAL gene, so as to promote

319 the production of secondary metabolites and enhance the resistance of plants, which is a mean of plant self-protection. It

320 could be seen from the regulation of phenylalanine metabolism that the up-regulated expression of synthesis related

321 enzymes could produce more phytoalexin--resveratrol and polydatin. Jasmonate can induce the expression of resistance

322 gene, unigenes homologous to genes of JAR1 were up-regulated, which promote the synthesis of jasmonate. Unigenes

323 homologous to COI-1、MYC2 were also up-regulated, which activate the expression of jasmonate responsive genes.

324 Unigenes homologous to regulatory protein NPR1 (NPR1) and transcription factor TGA were up-regulated, which were

325 related to the improvement of plant disease resistance. The up-regulated expression of 26 unigenes in the Biosynthetic

326 pathway of unsaturated fatty acids promoted the synthesis of unsaturated fatty acids for plant stress resistance. Hence it

327 could be inferred that although plants and endophytic fungi could coexist peacefully, the presence of endophytic fungi

328 still stimulated plants to mobilize the defense mechanism into defensive status.

329 Although RGT tissue culture seedlings were in the state of defensive, the growth of these seedlings were not inhibited.

330 The results of the experiment conformed that co-culture with Strain J-G could significantly promote the growth of RGT

331 tissue culture seedlings. This mainly because Strain J-G not only enhanced defense responses of RGT tissue culture

332 seedlings, but also promote the metabolism of them.

333 The variation of gene expression in the pathway of Cyanoamino acid metabolism not only promoted the metabolism of

334 nitrogen, but also enhanced metabolism and transformation of glycine, serine, threonine and cysteine. The up-regulated

335 expression of genes in the pathway of Glycine, serine and shreonine metabolism promoted the transformation between

336 amino acids as well. In Tyrosine metabolism pathway, the up-regulated expression of tyrosine transaminase, acetylase

337 and other enzymes could catalyze the synthesis of acetylacetone and fumarate, and the up-regulated expression of genes

338 of Hpal and succinate semialdehyde dehydrogenase / glutaric acid semialdehyde dehydrogenase promoted the synthesis

339 of succinate. Substances such as acetylacetone, fumarate and succinate could all enter the citric acid cycle to promote

340 material metabolism and energy formation. Through the regulation of these pathways of amino acid metabolism, it could

341 be inferred that the co-culture of Strain J-G and RGT tissue culture seedlings could promote the conversion between

342 amino acids and provide the necessary material basis for the growth of plants. Meanwhile, intermediate products were

343 generated to enter the citric acid cycle to accelerate metabolism, so as to promote the growth of RGT tissue culture

344 seedlings. 
345 The expression of 97 unigenes in Starch and sucrose metabolism were up-regulated. These unigenes homologous to 346 enzymes which promoted the formation of fructose and glucose and the accumulation of starch components. The

347 expression of 45 unigenes in pathway of Pentose and glucuronide interconversion were up-regulated which accelerated

348 glyceride metabolism, thus provided more energy for the growth of RGT tissue culture seedlings. Meanwhile, the

349 formation of glucuronic acid were also enhanced, which could provide more materials for synthesis of aminosaccharide

350 and ribose. It could be inferred from the variation of carbohydrate metabolism that co-culture of Strain J-G and RGT

351 tissue culture seedlings increased the substrates of respiration and promoted metabolism of plants. Therefore, it could

352 provide more materials and energy for the growth of RGT tissue culture seedlings.

353 In the Plant hormone signal transduction pathway, the expression of 108 unigenes were up-regulated and 48 unigenes

354 were down-regulated. The up-regulated expressions of unigenes homologous to responsive protein, responsive factors

355 and receptors to growth hormones, cytokinins and brassinosteroids enhanced the response to these hormones. Meanwhile,

356 the down-regulated expression of important genes inhibited the process of senescence. Though these phenomena it could

357 inferred that the growth and division of RGT tissue culture seedlings were accelerated, while senescence was delayed.

358 In addition, the function of gene repair was improved. Base-excision repair (BER) is the main approach to DNA damage

359 repair, which can treat small base damage caused by oxidative and alkylation damage. BER is usually defined as DNA

360 repair initiated by damage specific DNA glycosylase, and is performed by either of the two sub-pathways: short patch

361 BER and long patch BER. Each sub-pathway of BER depends on the formation of protein complexes, which gather at

362 DNA damage sites and promote restoration in a coordinated manner. This complex process seems to increase the

363 specificity and efficiency of the BER pathway, thus, the maintenance of genomic integrity is promoted by preventing the

364 accumulation of highly toxic repair intermediates. Most unigenes homologous to genes in the BER pathway were up-

365 regulated, therefore the repair function of DNA was improved, which provided a good guarantee for the growth of RGT

366 tissue culture seedlings. 
Acknowledgments

368 We are very grateful to Annoroad for their technical support. 
370 1. Zhang GQ, Zhao HP, Wang ZY, Cheng JR, Tang XM (2008) Research advances in chemical composition and 371 pharmacological activities of Rumex [J]. World Science and Technology-Modernization of Traditional Chinese Medicine 10(5): 86-93. https://doi.org/10.3969/j.issn.1674-3849.2008.05.020

2. Wang ZY, Chen JM, Wang QB, Kang YH, Cong Y, Liu YX (2009) Study on the chemical composition of Rumex gmelinii Turcz. (IV)[J]. Chinese Traditional and Herbal Drugs 40(09):1352-1355. https://doi.org/10.3321/j.issn: $\underline{0253-2670.2009 .09 .003}$

3. Wang ZY, Zuo YM, Kang YH, Cong Y, Song XL (2005) Study on the chemical composition of Rumex gmelinii Turcz. (II)[J]. Chinese Traditional and Herbal Drugs (11):1626-1627. https://doi.org/10.7501/j.issn.0253$\underline{2670.2005 .11 .2005011705}$

4. Guo SX. (2018). Research status and development trend of endophytic fungi in medicinal plants [J]. Mycosystema 37(1): 1-13. https://doi.org/10.13346/j.mycosystema.170252

5. Katoch M, Pull S (2017) Endophytic fungi associated with Monarda citriodora, an aromatic and medicinal plant and their biocontrol potential [J]. Pharmaceutical Biology. 2017; 55(1): 1528-1535.

6. Jia M, Chen L, Xin HL, Zheng CJ, Rahman K, Han T, Qin LP (2016) A friendly relationship between endophytic https://doi.org/10.1080/13880209.2017.1309054 fungi and medicinal plants: a systematic review.front. microbial (7): 906. https://doi.org/10.3389/fmicb.2016.00906

7. Waqas M, Khan A L, Kamran M, Hamayun M, Kang SM, Kim YH (2012) Endophytic fungi produce gibberellinsand indoleacetic acid and promotes host-plant growth during stress. Molecules 17(9):10754-10773. https://doi.org/10.3390/molecules170910754

8. Xing XK (2018) Endophytic fungal resources of medicinal plants: a treasure trove to be developed [J]. Mycosystema 37(1):14-21. https://doi.org/10.13346/j.mycosystema.170250

9. Chen BB, Wang M, Hu YL, Lin ZP, Yu RM, Huang LQ (2011) A Preliminary study on the growth promoting effect of Rehmannia Glutinosa endophytic fungi [J]. China Journal of Chinese Materia Medica 36(9):1137-1140. https://doi.org/doi: CNKI:SUN:ZGZY.0.2011-09-008

10. Zhou LS, Tang S, Guo SX (2018) Endophytic fungus cladosporium sp. effect on Salvia Miltiorrhiza growth and salvianolic acid content [J]. Mycosystema 37(1): 95-101. https://doi.org/10.15886/j.cnki.rdswxb.2018.04.012 
11. Zhou K, Wu WD, Song XQ, Zhou Y (2018) Screening and identification of endophytic fungi from Anoectochilus Roxburghii [J]. Journal of Tropical Biology 9(04): 440-444.https://doi.org/10.15886/j.cnki.rdswxb.2018.04.012

12. Wu XL, Cui GL, Liu F, Li LY (2018) Isolation and molecular identification of endophytic fungi from Artemisia Annиa and study on the growth promoting effect of Trichoderma Viride on Artemisia Annua [J]. Journal of Tropical and Subtropical Botany 26(01): 56-64. https://doi.org/10.11926/jtsb.3768

13. Liu J, Liu YM, Xv ZC, Wang ZY, Huang YL, Deng ZJ (2018) Studies on the diversity of endophytic fungi of Santalum Album and its antibacterial and growth-promoting properties [J]. China Journal of Chinese Materia Medica. 43(17): 3477-3483. https://doi.org/10.19540/j.cnki.cjcmm.20180727.001

14. Asaf LS, Khan AL, Waqas M, Kang SM, Hamayun M, Lee IJ, Hussain A (2019) Growth-promoting bioactivities of Bipolaris sp. CSL-1 isolated from Cannabis sativa suggest a distinctive role in modifying host plant phenotypic plasticity and functions[J]. Acta Physiologiae Plantarum 41(5): 65-73. https://doi.org/10.1007/s11738-019-2852-7

15. Yuan M, Tan SJ, Sun JG (2016) Isolation, identification and biological characteristics of endophytic nitrogen-fixing

16. Prisana Wonglom, Shin-ichi Ito, Anurag Sunpapao (2020) Volatile organic compounds emitted from endophytic fungus Trichoderma asperellum T1 mediate antifungal activity, defense response and promote plant growth in lettuce ( Lactuca sativa )[J]. Fungal Ecology. 2020; (43).https://doi.org/10.1016/j.funeco.2019.100867

17. Sun X, Wang N, Li P, Jiang ZY, Liu XY, Wang MC, Su ZZ, Zhang CL, Lin FC, Liang Y (2020) Endophytic fungus Falciphora oryzae promotes lateral root growth by producing indole derivatives after sensing plant signals [J]. Plant, cell \& environment 43(2): 358-373. https://doi.org/10.1111/pce.13667

18. Wang XL, Huang LQ, Yuan Y, Cha LP (2015) Research progress on transcriptome of medicinal plants [J]. China Journal of Chinese Materia Medica 40(11): 2055-5012.https://doi.org/10.4268/cjcmm20151101

19. Zhang SB, Hou L, Pan Q, Wang XM, Cui QH, Tian JZ, Ma LY (2014) Research progress of high-throughput transcriptome of traditional chinese medicine. [J]. China Journal of Chinese Materia Medica 39(9):1553-1558. https://doi.org/10.4268/cjemm20140902

20. Liu KH, Ding XW,Narsing RMP,Zhang B, Zhang GZ, Liu FH, Liu BB, Xiao M, Li WJ (2017) Morphological and transcriptomic analysis reveals the osmoadaptive response of endophytic fungus Aspergillus montevidensis ZYD4 to high salt stress [J]. Frontiers in microbiology 8: 1789-1799. https://doi.org/10.3389/fmicb.2017.01789 
21. Lamdan NL, Shalaby S, Ziv T, Kenerley CM, Horwitz BA (2015) Secretome of Trichoderma interacting with maize

425 roots: role in induced systemic resistance [J]. Molecular and Cellular Proteomics 14(4):1054-1063.

426 https://doi.org/10.1074/mcp.M114.046607

\section{Figure Legends}

428 Figures

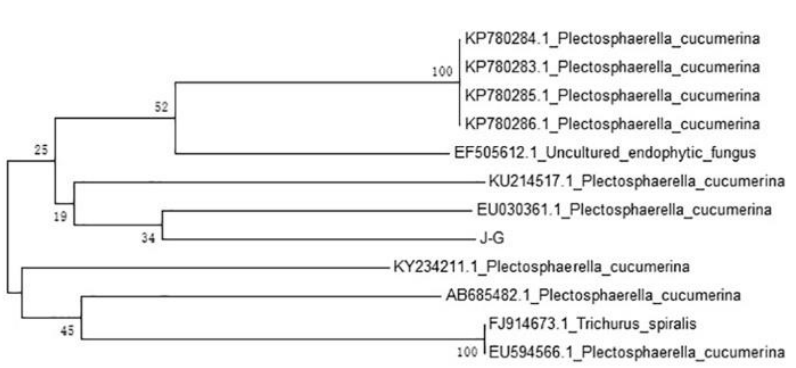

$\longmapsto 0.5$

429

$430 \quad$ Fig.1 Endophytic fungus Strain J-G
A

$\mathbf{A}$
A

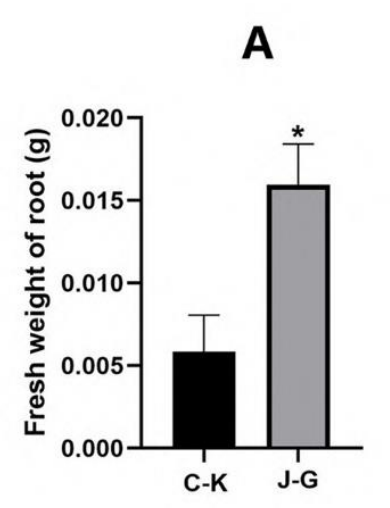

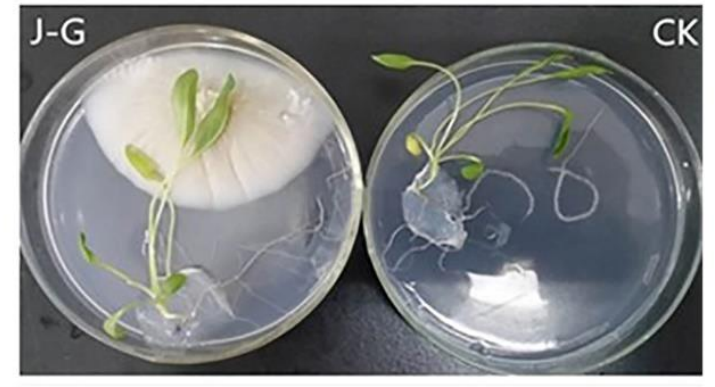

B
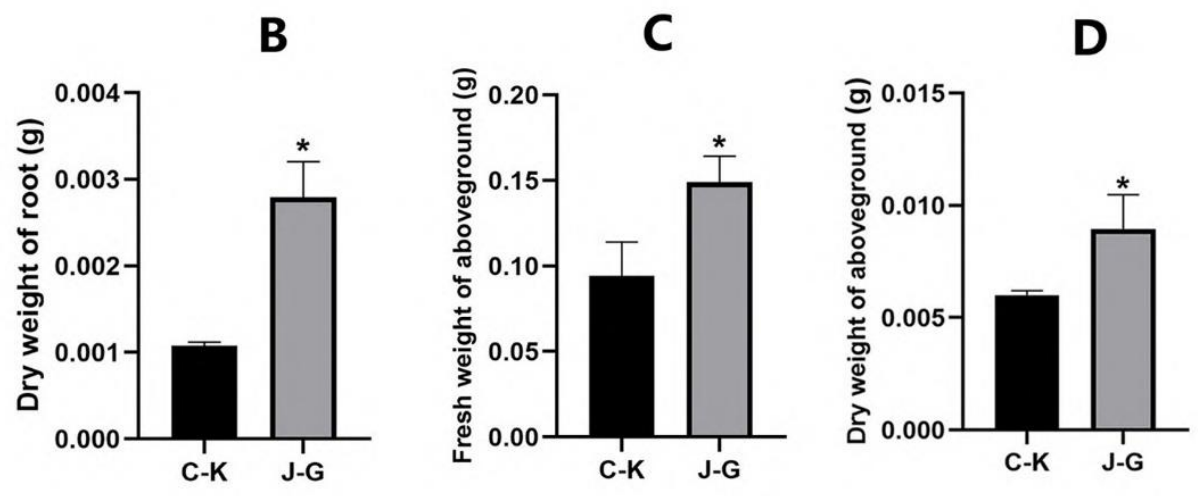

433 Fig. 2 Effects of Strain J-G on Various Physiological Indexes of Rumex gmelinii Turcz. Cultured Seedlings $(n=3 * P<0.05)$

* represents a significant difference from the blank control (CK) 
A

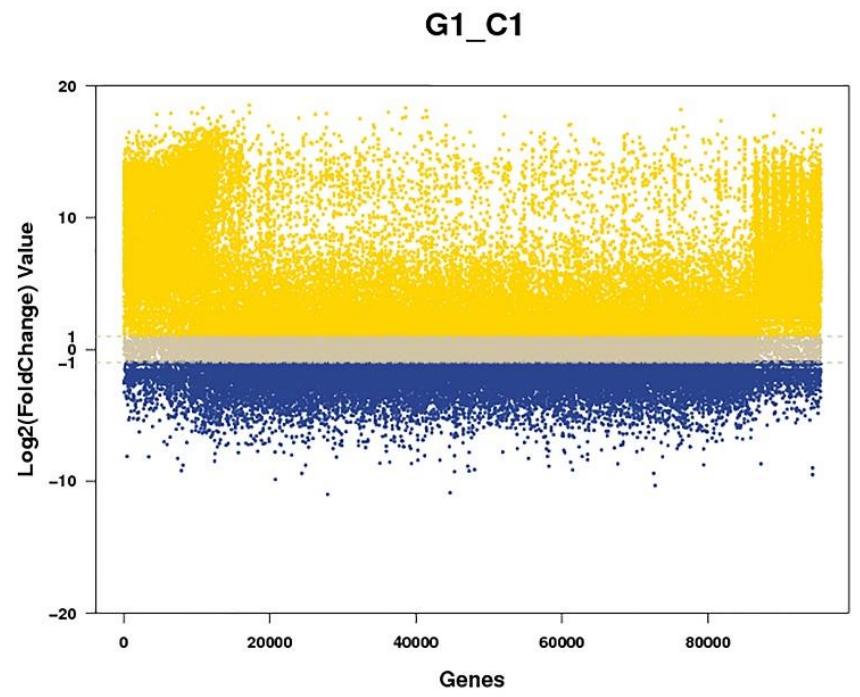

B

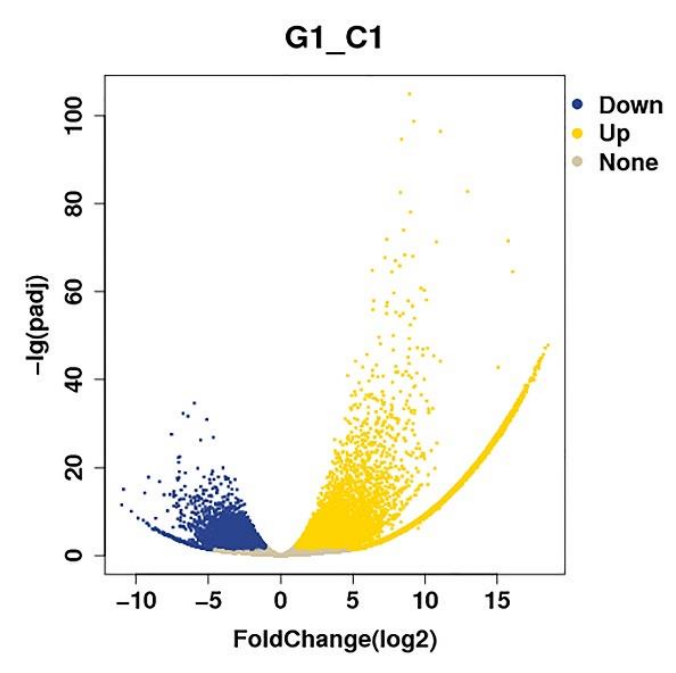

436

437 Fig. 3 log2foldchange and Volcanic map of G1-C1 comparison

438 A Scatter diagram of log2foldchange value distribution ; B Volcanic map 


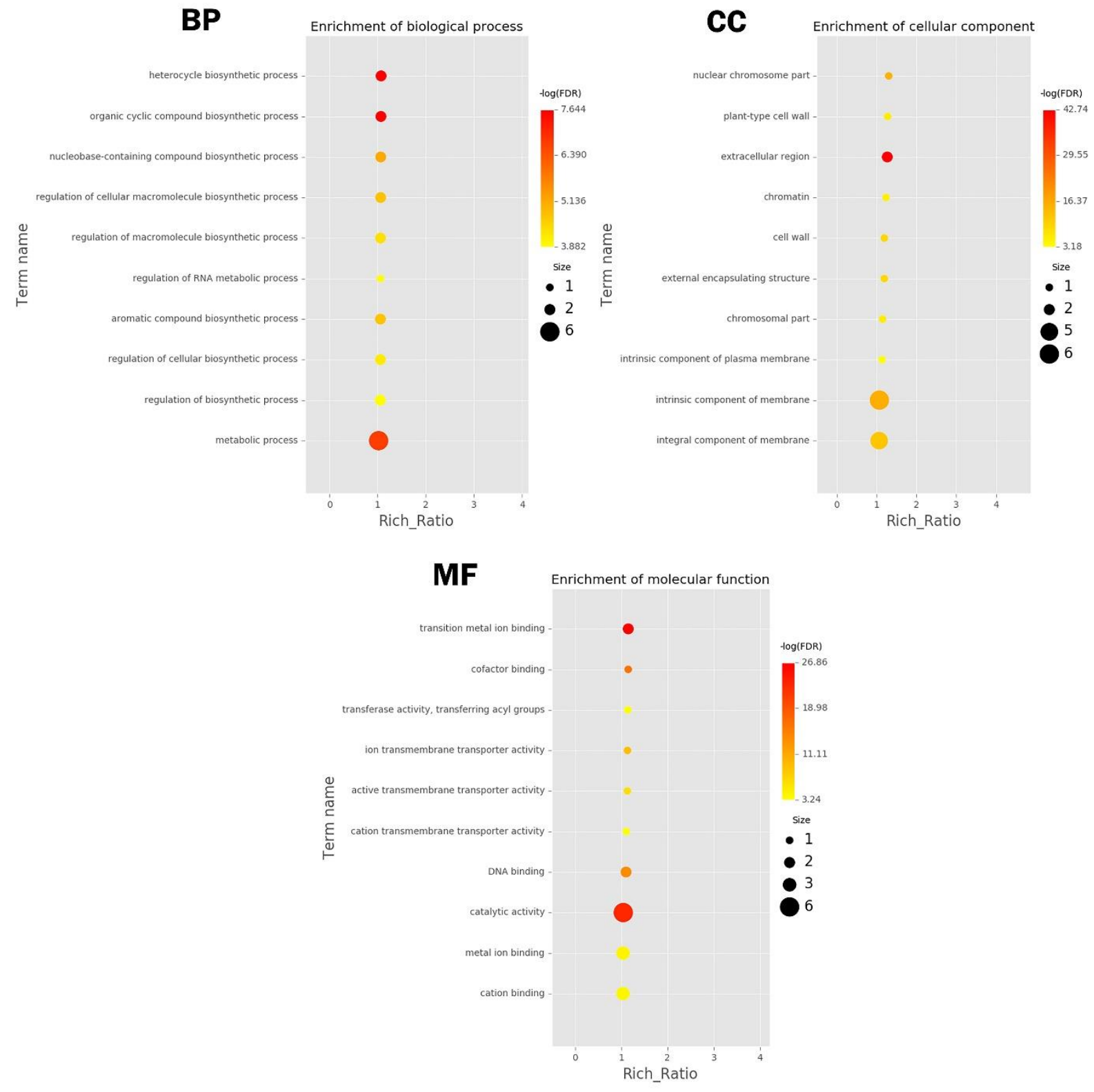

Fig. 4 Bubble diagram of the $10 \mathrm{GO}$ items with the highest enrichment significance 


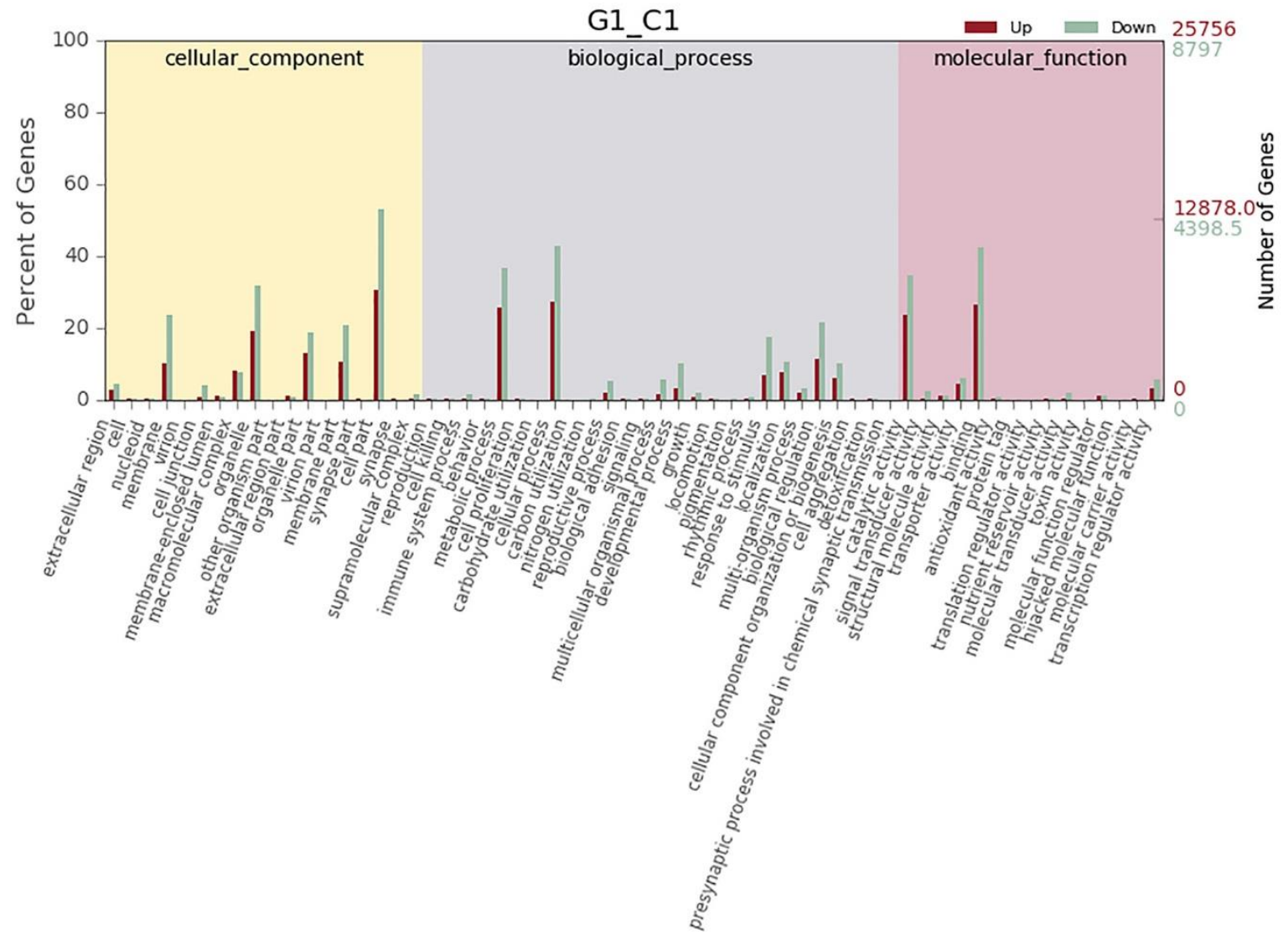

Fig. 5 Statistics of annotation results of different expressed genes in secondary GO items.

\section{KEGG}

Phenylpropanoid biosynthesis

Circadian rhythm - plant

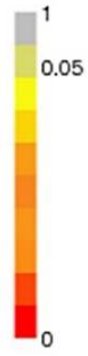

Steroid biosynthesis

Base excision repair

Pentose and glucuronate interconversions

Plant hormone signal transduction

Biosynthesis of unsaturated fatty acids

alpha-Linolenic acid metabolism

Glycine, serine and threonine metabolism

Isoquinoline alkaloid biosynthesis 

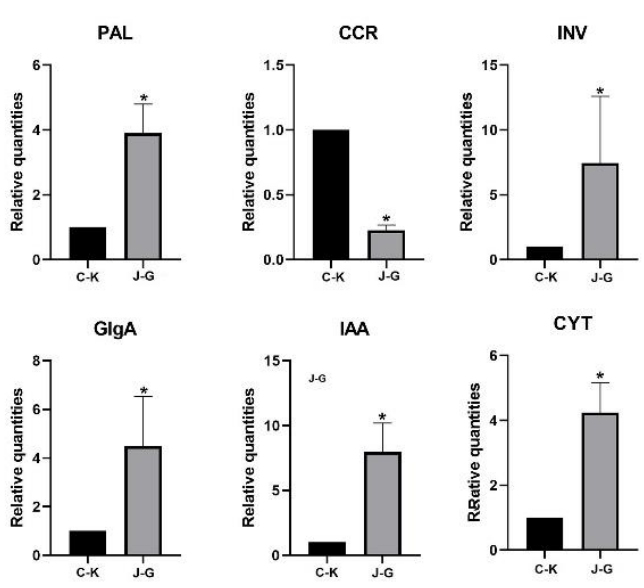

445

446 Fig. 7 Different expression of each gene $(p<0.05, n=3)$

447 Tables

448 Table 1 Total RNA test results of samples

\begin{tabular}{llllllll}
\hline Sample & $\begin{array}{l}\text { Concentration } \\
(\mathrm{ng} / \mu \mathrm{L})\end{array}$ & $\begin{array}{l}\text { Volume } \\
(\mu \mathrm{L})\end{array}$ & $\begin{array}{l}\text { Total } \\
(\mu \mathrm{g})\end{array}$ & OD260/280 & OD260/230 & $25 \mathrm{~S} / \mathrm{18S}^{*}$ & $\mathrm{RIN}^{*}$ \\
\hline C1a & 1245 & 25 & 31.1 & 2.1 & 1.9 & 1.2 & 8.4 \\
C1b & 1002 & 25 & 25.1 & 2.1 & 1.9 & 1.3 & 8.1 \\
C1c & 594 & 25 & 14.9 & 2.1 & 1.9 & 1.6 & 8.9 \\
G1a & 480 & 25 & 12.0 & 2.1 & 0.8 & 1.3 & 8.9 \\
G1b & 387 & 25 & 9.7 & 2.1 & 0.9 & 1.0 & 7.1 \\
G1c & 423 & 25 & 10.6 & 2.1 & 1.5 & 1.4 & 8.4 \\
\hline
\end{tabular}

449 $\mathrm{RIN}^{*}$ : RNA Intergrity Number, RNA integrity index

454 Table 2 Summary of some differently expressed genes of RGT co-cultured with endophytic fungus Strain J-G 


\begin{tabular}{|c|c|c|c|}
\hline Unigene ID & Putative funtion & $\log 2$ fold & Pathway \\
\hline \multicolumn{4}{|l|}{ Phenylpropanol biosynthesis } \\
\hline TRINITY_DN33839_c3_g2 & Phenylalanine ammonia-lyase (PAL) & +4.8 & Phenylpropanol biosynthesis \\
\hline TRINITY_DN37056_c0_g2 & cinnamoyl-CoA reductase (CCR) & -2.9 & Phenylpropanol biosynthesis \\
\hline TRINITY_DN31663_c0_g1 & $\begin{array}{l}\text { Shikimate O-hydroxy-- } \\
\text { cinnamoytransferase }\end{array}$ & $-3.2(9.6)$ & Phenylpropanol biosynthesis \\
\hline
\end{tabular}

\section{Cyanamide acid metabolism}

\begin{tabular}{|c|c|c|c|}
\hline TRINITY_DN29473_c0_g4 & Formamidase & +13.02 & NH3 synthesis and nitrogen metabolism \\
\hline TRINITY_DN25667_c0_g1 & Glycine methyl transferase (GlyA) & +13.34 & $\begin{array}{l}\text { Metabolism and transformation of } \\
\text { amino acids }\end{array}$ \\
\hline
\end{tabular}

\section{Tyrosine pathway}

\begin{tabular}{|c|c|c|c|}
\hline TRINITY_DN36945_c0_g1 & Tyrosine aminotransferase & +2.99 & $\begin{array}{l}\text { Transformation of 4-hydroxy- } \\
\text { phenylpyruvate with tyrosine }\end{array}$ \\
\hline TRINITY_DN12337_c0_g1 & $\begin{array}{l}\text { Aromatic amino acid } \\
\text { aminotransferase I }\end{array}$ & +13.13 & $\begin{array}{l}\text { Transformation of 4-hydroxy- } \\
\text { phenylpyruvate with tyrosine }\end{array}$ \\
\hline TRINITY_DN14878_c1_g1 & $\begin{array}{l}\text { Phosphohistidine aminotransferase } \\
\text { (HisC) }\end{array}$ & +14.38 & $\begin{array}{l}\text { Transformation of 4-hydroxy- } \\
\text { phenylpyruvate with tyrosine }\end{array}$ \\
\hline TRINITY_DN23316_c0_g1 & Aspartate aminotransferase & +11.53 & $\begin{array}{l}\text { Transformation of 4-hydroxy- } \\
\text { phenylpyruvate with tyrosine }\end{array}$ \\
\hline TRINITY_DN10312_c0_g1 & $\begin{array}{l}\text { 4-hydroxyphenylpyruvate } \\
\text { dioxygenase (HPD) }\end{array}$ & +8.89 & $\begin{array}{l}\text { Material metabolism and energy } \\
\text { formation }\end{array}$ \\
\hline TRINITY_DN14117_c0_g1 & maleylacetate isomerase (MaiA) & +12.14 & $\begin{array}{l}\text { Material metabolism and energy } \\
\text { formation }\end{array}$ \\
\hline TRINITY_DN44336_c0_g1 & Fumarylacetoacetase & +7.71 & $\begin{array}{l}\text { Material metabolism and energy } \\
\text { formation }\end{array}$ \\
\hline TRINITY_DN2328_c0_g1 & $\begin{array}{l}\text { 4- hydroxy- } 2 \text { - oxyheptanediate } \\
\text { aldehydase (Hpal) }\end{array}$ & +9.19 & $\begin{array}{l}\text { Material metabolism and energy } \\
\text { formation }\end{array}$ \\
\hline TRINITY_DN15731_c0_g1 & $\begin{array}{l}\text { Succinate semialdehyde } \\
\text { dehydrogenase/glutarate } \\
\text { semialdehyde dehydrogenase (GabD) }\end{array}$ & +16.98 & $\begin{array}{l}\text { Material metabolism and energy } \\
\text { formation }\end{array}$ \\
\hline TRINITY_DN23770_c0_g2 & $\begin{array}{l}\text { Monoamine oxidase, alcohol } \\
\text { dehydrogenase and aldehyde } \\
\left.\text { dehydrogenase (NAD }(\mathrm{P})^{+}\right)\end{array}$ & +9.63 & $\begin{array}{l}\text { Metabolism and conversion of amino } \\
\text { acids }\end{array}$ \\
\hline
\end{tabular}




$\begin{array}{llll}\text { Starch and sucrose metabolism } & & \\ \text { TRINITY_DN27483_c0_g5 } & \beta \text {-fructofuranosidase (INV) } & +1.24(2.4) & \text { 6-phosphate-glucose formation } \\ \text { TRINITY_DN10513_c0_g1 } & \alpha \text {-glucosidase } & +8.41 & \text { Conversion between saccharides } \\ \text { TRINITY_DN33633_c0_g3 } & \text { Glucan 1,3- } \beta \text {-glucosidase } & +3.73 & \text { Conversion between saccharides } \\ \text { TRINITY_DN23967_c0_g2 } & 1,3 \text { - } \beta \text {-glucanase } & +15.13 & \text { Conversion between saccharides } \\ \text { TRINITY_DN54426_c0_g1 } & \text { Endoglucanase } & +10.89 & \text { Conversion between saccharides } \\ \text { TRINITY_DN55106_c0_g1 } & \text { Cellulose 1,4- } \beta \text {-fibreglucosidase } & +8.47 & \text { Conversion between saccharides } \\ \text { TRINITY_DN15591_c0_g1 } & \alpha-\text { trehalase } & +10.36 & \text { Conversion between saccharides } \\ \text { TRINITY_DN27249_c0_g2 } & \text { Starch synthetase (GlgA) } & +1.97 & \text { Starch synthesis }\end{array}$

Pentose and glucuronide interconversion pathway

$\begin{array}{llll}\text { TRINITY_DN19953_c0_g3 } & \text { Galacturonidase } & +8.91 & \text { diaminogalactose to galactose } \\ \text { TRINITY_DN32703_c1_g6 } & \begin{array}{l}\text { L-threonine-3-deoxyhexanoic acid } \\ \text { aldolase (GAAC) }\end{array} & +13.86 & \text { provide energy } \\ \text { TRINITY_DN2277_c0_g1 } & \begin{array}{l}\text { Alcohol dehydrogenase (NADP+) } \\ \text { (AKR1A1) }\end{array} & +9.26 & \text { D-Glucuronate formation } \\ \text { TRINITY_DN27315_c0_g3 } & \begin{array}{l}\text { UTP-glucose-1- } \\ \text { phosphouridinyltransferase (UGP2) }\end{array} & +15.79 & \text { UDP-D-Glucuronate } \\ \text { TRINITY_DN26407_c0_g2 } & \begin{array}{l}\text { UDP-glucose-6-dehydrogenase } \\ \text { (UGDH) }\end{array} & +0.62 & \text { formation } \\ \text { TRINITY_DN27361_c0_g2 } & \text { UDP glycopyrophosphorylase (USP) } & +0.51 & \text { formation } \\ \text { TRINITY_DN12877_c0_g1 } & \beta \text {-glucuronidase } & +9.52 & \text { Glucoronate formation }\end{array}$

\section{Steroid biosynthetic pathway}

TRINITY_DN36602_c0_g1 $\quad \begin{aligned} & \text { Farnesyl diphosphate farnesyl } \\ & \text { transferase (FDFT1) }\end{aligned} \quad$ Steroid biosynthetic

Plant hormone signal transduction pathway 


\begin{tabular}{|c|c|c|c|}
\hline TRINITY_DN26407_c0_g2 & $\begin{array}{l}\text { Auxin influx carrier (AUX1 LAX } \\
\text { family) }\end{array}$ & +0.62 & Growth-promoting hormones response \\
\hline TRINITY_DN24511_c0_g1 & Auxin-responsive protein IAA (IAA) & +2.89 & Growth-promoting hormones response \\
\hline TRINITY_DN37131_c0_g1 & Auxin response factor $(\mathrm{k} 4486)$ & +4.46 & Growth-promoting hormones response \\
\hline TRINITY_DN27355_c2_g1 & $\begin{array}{l}\text { Auxin responsive GH3 gene } \\
\text { family(GH3) }\end{array}$ & +0.64 & Growth-promoting hormones response \\
\hline TRINITY_DN24352_c0_g1 & SAUR family protein (SAUR) & +5.98 & Growth-promoting hormones response \\
\hline TRINITY_DN26677_c2_g1 & $\begin{array}{l}\text { Transport inhibitor responder } 1 \\
\text { (TIR1) }\end{array}$ & -2.61 & Growth-promoting hormones response \\
\hline TRINITY_DN28612_c0_g1 & $\begin{array}{l}\text { Arabidopsis histidine kinase 2/3/4 } \\
\text { (cytokinin receptor) (AHK2_3) }\end{array}$ & $+5.44(43.64)$ & Cytokinin response \\
\hline TRINITY_DN23829_c0_g1 & $\begin{array}{l}\text { Histidine-containing phosphotransfer } \\
\text { peotein (AHP) }\end{array}$ & +8.21 & Cytokinin response \\
\hline TRINITY_DN31927_c0_g3 & $\begin{array}{l}\text { Two-component response regulator } \\
\text { ARR-B family (ARR-B) }\end{array}$ & +3.47 & Cytokinin response \\
\hline TRINITY_DN25935_c0_g2 & $\begin{array}{l}\text { Two-component response regulator } \\
\text { ARR-A family }\end{array}$ & +8.95 & Cytokinin response \\
\hline TRINITY_DN36970_c0_g1 & Ethylene-insensitive protein 2 (EIN2) & -0.16 & delay plant senescence \\
\hline TRINITY_DN24552_c0_g1 & $\begin{array}{l}\text { Ethylene-insensitive protein } 2 \text { (EBF1 } \\
\text { 2) }\end{array}$ & -2.85 & delay plant senescence \\
\hline TRINITY_DN26260_c0_g1 & $\begin{array}{l}\text { Ethylene-responsive transcription } \\
\text { factor } 1 \text { (ERF1) }\end{array}$ & -2.27 & delay plant senescence \\
\hline TRINITY_DN30065_c0_g2 & BAK1 & +2.64 & Brassinosteroids response \\
\hline TRINITY_DN32023_c0_g1 & BRI1 & +3.71 & Brassinosteroids response \\
\hline TRINITY_DN34069_c0_g2 & BSK & +2.76 & Brassinosteroids response \\
\hline TRINITY_DN32302_c2_g1 & $\mathrm{TCH} 4$ & +3.66 & Brassinosteroids response \\
\hline TRINITY_DN24841_c0_g2 & CYCD3 & +5.63 & Brassinosteroids response \\
\hline TRINITY_DN33321_c0_g1 & $\begin{array}{l}\text { Jasmonic acid-amino synthetase } \\
\text { (JAR1) }\end{array}$ & +2.87 & Jasmonic acid synthesis \\
\hline TRINITY_DN25813_c0_g1 & $\begin{array}{l}\text { Coronatine-insensitive protein } 1 \\
\text { (COI-1) }\end{array}$ & +2.91 & Plant hormone signal transduction \\
\hline
\end{tabular}




$\begin{array}{llll}\text { TRINITY_DN36389_c1_g2 } & \begin{array}{l}\text { Jasmonate ZIM domain-containing } \\ \text { protein (JAZ) }\end{array} & +2.61 & \text { Plant hormone signal transduction } \\ \text { TRINITY_DN39357_c0_g1 } & \text { Transcription factor MYC2 (MYC2) } & +2.63 & \text { Plant hormone signal transduction } \\ \text { TRINITY_DN43631_c3_g2 } & \text { Regulatory protein NPR1 (NPR1) } & +3.44 & \text { improvement of plant disease resistance } \\ \text { TRINITY_DN30786_c1_g1 } & \text { Transcription factor TGA } & +4.08 & \text { improvement of plant disease resistance }\end{array}$




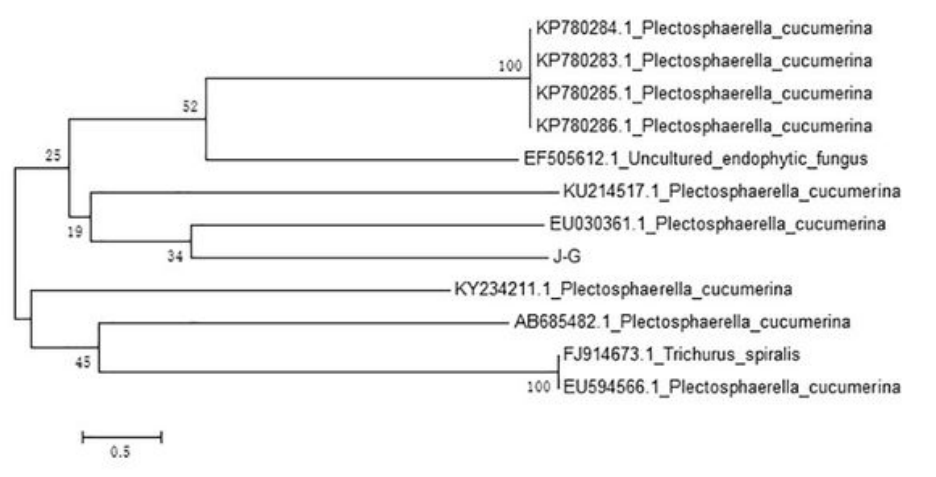

A

\section{Figure 1}

Endophytic fungus Strain J-G
B

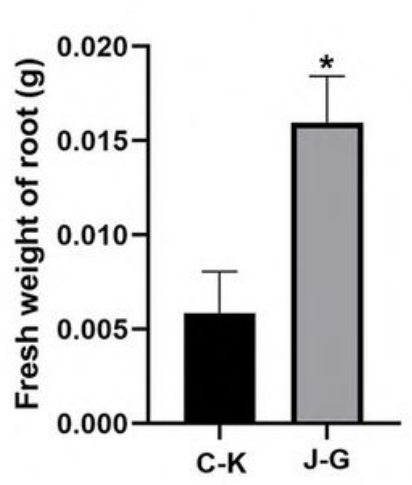

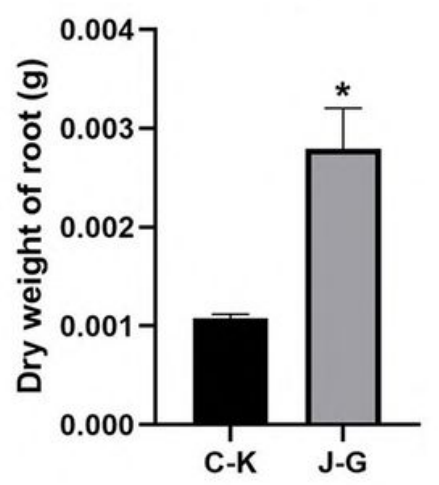

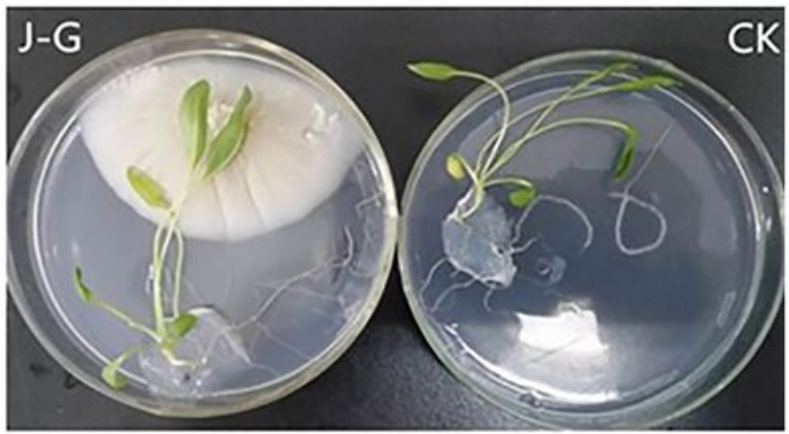

B
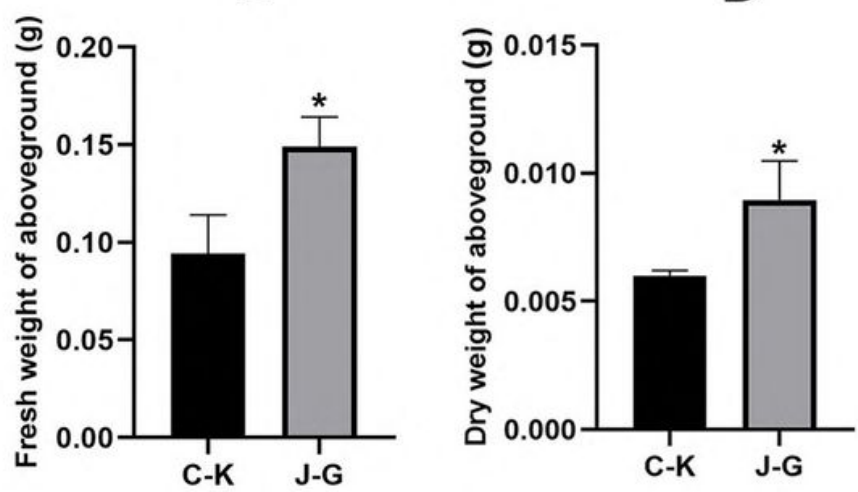

Figure 2

Effects of Strain J-G on Various Physiological Indexes of Rumex gmelinii Turcz. Cultured Seedlings ( $\mathrm{n}=3$ * $\mathrm{P}<0.05)$ * represents a significant difference from the blank control (CK) 
A

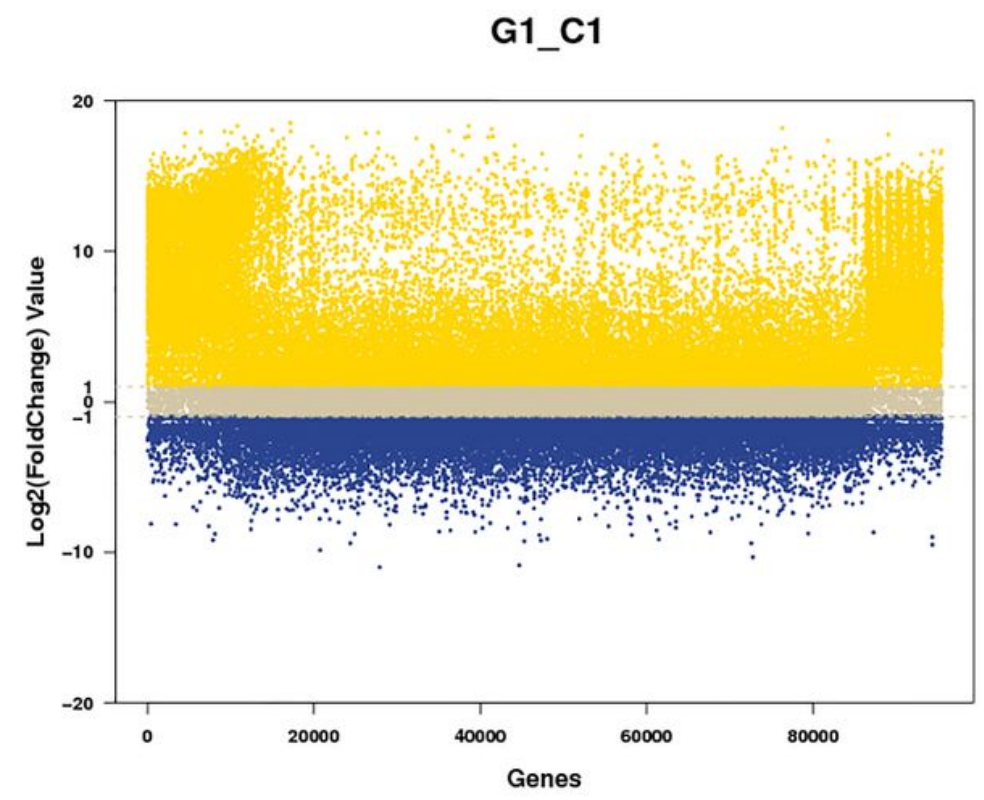

B

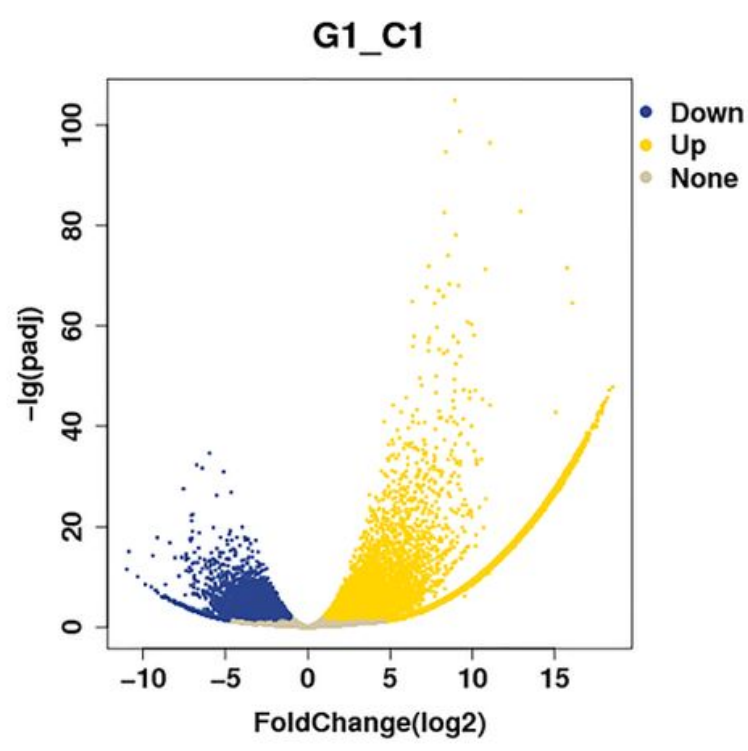

Figure 3

log2foldchange and Volcanic map of G1-C1 comparison A Scatter diagram of log2foldchange value distribution $\mathbb{B}$ Volcanic map 


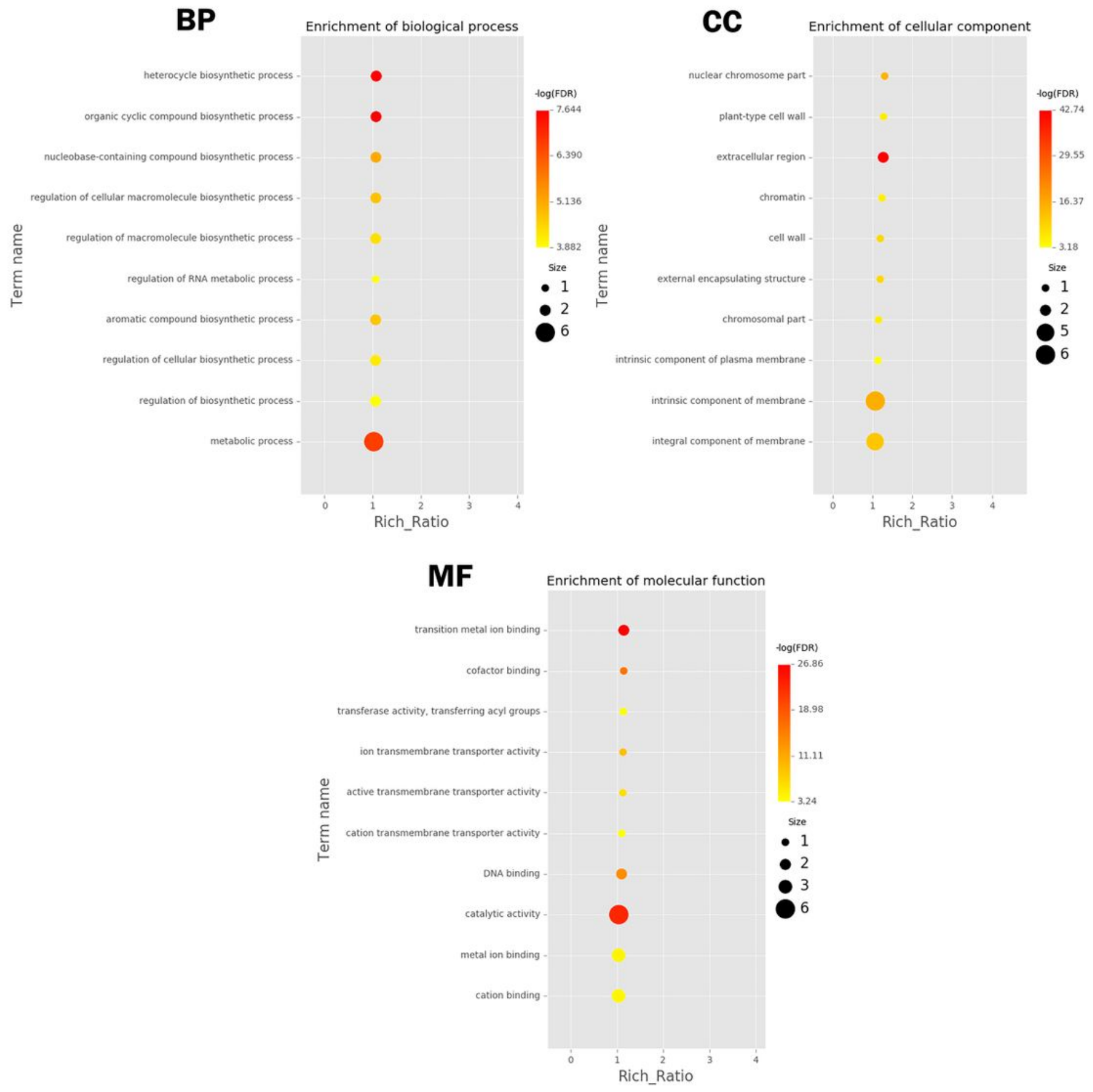

Figure 4

Bubble diagram of the $10 \mathrm{GO}$ items with the highest enrichment significance 


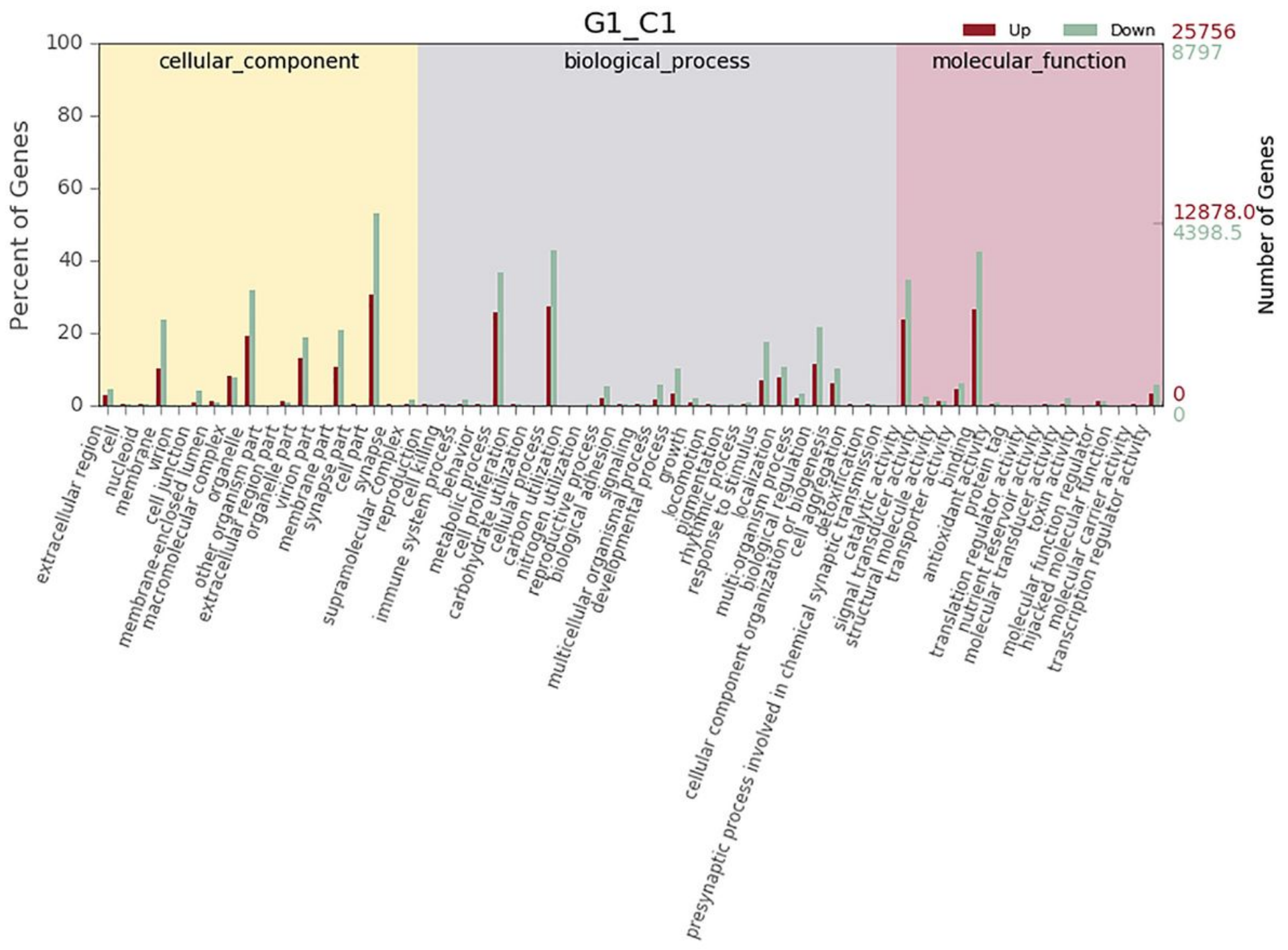

Figure 5

Statistics of annotation results of different expressed genes in secondary GO items. 


\section{KEGG}

Phenylpropanoid biosynthesis

Circadian rhythm - plant

Oxidative phosphorylation

Cyanoamino acid metabolism

Tyrosine metabolism

Starch and sucrose metabolism

Phenylalanine metabolism

Steroid biosynthesis

Base excision repair

Pentose and glucuronate interconversions

Plant hormone signal transduction

Biosynthesis of unsaturated fatty acids

alpha-Linolenic acid metabolism

Glycine, serine and threonine metabolism

Isoquinoline alkaloid biosynthesis

Figure 6

Significance of KEGG enrichment 
PAL

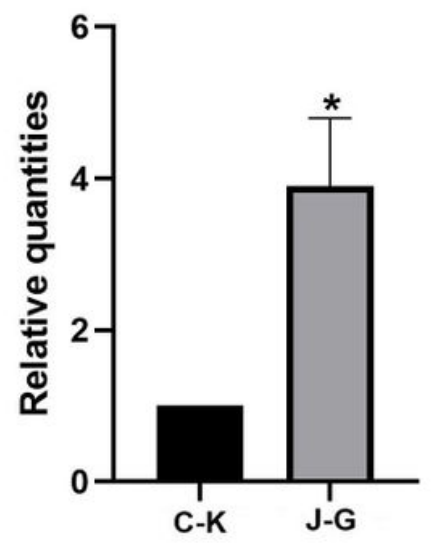

GlgA

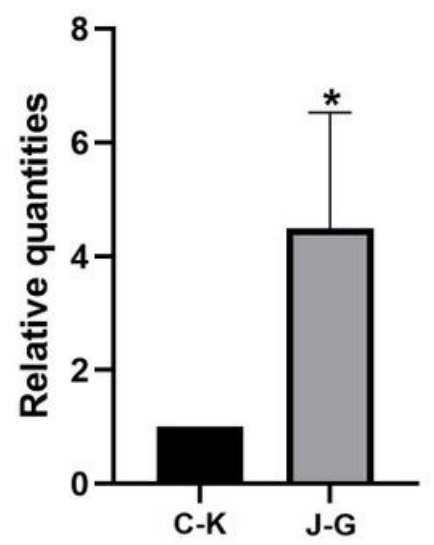

CCR

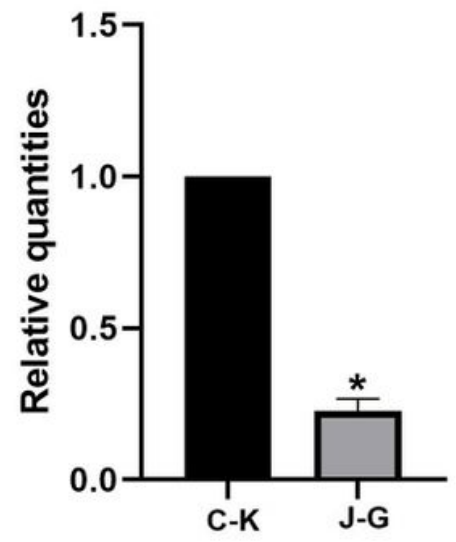

IAA

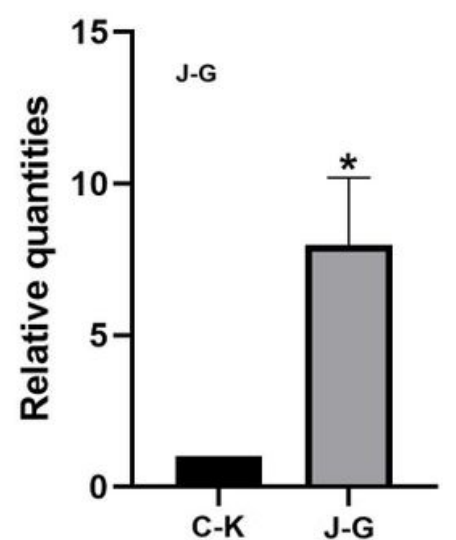

INV

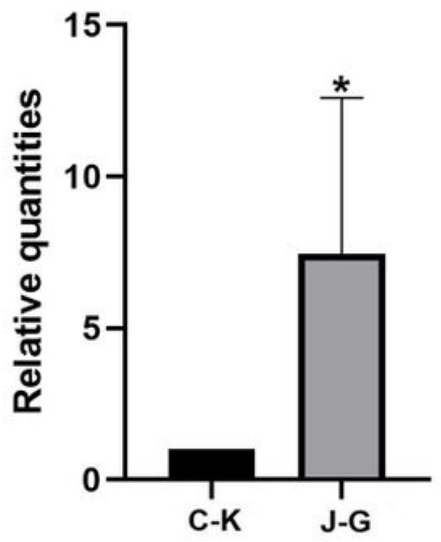

CYT

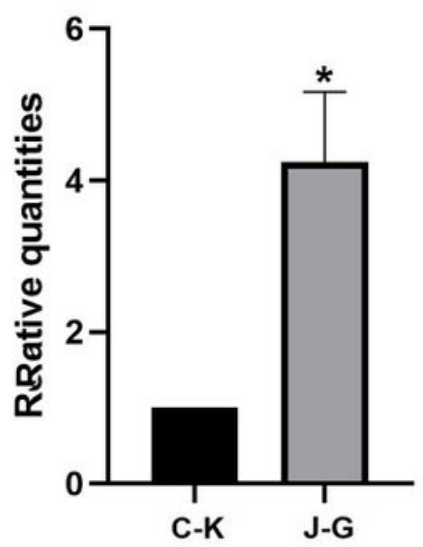

Figure 7

Different expression of each gene $(p<0.05, n=3)$ 